\title{
SIMPLE SURGICAL PROCEDURES FOR RELIEF OF FOOT SPASTICITY
}

\author{
By Paul Masse, M.D. \\ Centre de Rééducation Motrice de Fontainebleau, France
}

IN paraplegic patients, walking and even sitting can be made difficult by isolated spasm of the feet, mainly spasm of the triceps surae and tibialis posterior. Very often, foot spasticity induces total spasticity. Local action on the triceps surae is frequently used, but in several cases section or lengthening causes a disabling dorsiflexion of the foot. It is certain that a completely flaccid foot is more convenient than a partially spastic one. This flaccidity can be achieved by two simple procedures: division of all tendons of the foot or division of the nerves, in particular of the two terminal branches of the sciatic nerve.

\section{DIVISION OF THE TENDONS (Pan-tenotomy)}

This division is made at the level of the ankle joint through three incisions:

(a) Through a 2 -inch long anterior vertical incision-section of the tibialis anterior and both extensors of the toes.

(b) Through a postero-medial incision behind the medial malleolus-division of the tibialis posterior, flexors of the toes and Achilles tendon; by the same incision, the tibialis posterior nerve can be isolated and resected.

(c) Through the postero-lateral incision-behind the lateral malleolus division of peroneus longus and brevis.

\section{RESECTION OF THE SCIATIC NERVE}

By a short transverse incision at the highest part of the popliteal area, the two terminal branches of the nerve are isolated and resected.

Both operations are made easier by the use of a tourniquet from which we never had any trouble.

We used these techniques on nine patients, as shown in the following table:

TABLE

Operations

\begin{tabular}{|c|c|c|c|}
\hline & & Patients & Limbs \\
\hline Pan-tenotomy & . & 2 & 3 \\
\hline+ arthrodesis of toes & . & I & 2 \\
\hline + tibial neurectomy & . & 2 & 4 \\
\hline Unilateral pan-tenotomy & ! & & \\
\hline Sciatic neurectomy & i & 1 & 2 \\
\hline Sciatic neurectomy & - & 3 & 6 \\
\hline & & 9 & I7 \\
\hline
\end{tabular}


Pan-tenotomy. This procedure was used in six patients. The first one was operated upon in 1958 . In 1957 , he had a resection of the nerves of the triceps surae but following this was still handicapped by a varus deformity and spasm of the dorsiflexors. Six years after pan-tenotomy, in spite of a Tio lesion, he walks every day.

However, walking is not always the goal of the procedure. A tetraplegic patient, 40 years old, with flexion contracture of both hips and knees, could not even sit comfortably because of equino-varus deformity and flexion contractures of the toes. Division of the tendons allowed him to sit but the flexion contractures of the toes had to be corrected by arthrodesis of all the joints except the M.P. joints. The result was good.

Following section of the tendons at the level of the ankle, the short flexors of the toes still remain active, and this causes disabling irritative areas on the dorsal aspect of the toes. This is the reason why in two patients ( 4 limbs) we combined tendon sections with a resection of the posterior tibial nerve through the posteromedial incision used to cut the tibialis posterior and long flexors of the toes.

Sciatic Neurectomy. Though sciatic neurectomy has been used by several authors (Freeman, Hardy, Comarr), because no detailed results were given in their publications, we were not very enthusiastic about this procedure. The fear of producing trophic disturbances led us to undertake an experimental study on cats which will be published later. This study showed that trophic disturbances were not increased in animals by sciatic resection.

We performed this procedure in four patients with complete relief of footspasticity. On one occasion, we performed neurectomy on one side and tenotomies on the other for comparison. On the tenotomised side, the tibialis posterior nerve had not been cut and the flaccidity is less than on the neurotomised side, but on the latter side muscular atrophy is obvious.

\section{CONCLUSIONS}

It is for the moment impossible to say what is the best procedure for relief of foot spasticity. Nothing allows us to choose one or the other. Indications are the same. Advantages can be summarised as follows:

Tenotomy

No muscular atrophy

No cutaneous risk
Neurectomy

Simplicity

Better scar

Paralysis of short flexors

Supression of reflexogenic area

Whatever the technique used, we established flaccidity, a good balance and easier fixing of the foot in the brace.

\section{SUMMARY}

This paper deals with surgical procedures for relief of foot spasticity which include division of tendons (Pan-tenotomy) and resection of the sciatic nerve.

At present, it is impossible to say which method is the best procedure. The advantage of tenotomy is that there is no muscular atrophy or cutaneous risk, while neurectomy has the advantage of being simple, resulting in a better scar and producing paralysis of short flexors and suppression of the reflexogenic area. 
RÉSUMÉ

Le sujet de cet article est celui des interventions chirurgicales contre spasticité du pied comprenant la section des tendons (Pan-tenectomie), ainsi que la section du nerf sciatique.

A l'heure actuelle, il est impossible de savoir qu'elle est la methode meilleure. Les avantages de la tenotomie est qu'elle n'entraine pas d'atrophie musculaire ou de risques cutanes, alors que la neurectomie a l'avantage d'être simple, produisant une cicatrice meilleure, ainsi qu'une paralysie des courts flechisseurs, et la supression de l'aire reflexogene.

\section{ZUSAMMENFASSUNG}

Chirurgische Massnahmen in der Behandlung der Fuss-spasmen werden beschrieben, besonders Tenotomie (Pan-Tenotomie) und Resektion des N. ischiaticus.

Wir können noch nicht sagen, welche Methode vorzuziehen ist. Tenotomie verursacht keine Muskelatrophie oder Hautschädigung. Neurektomie bietet den Vorteil, dass sie einfacher ist, bessere Narben hinterlässt und Lähmung der kurzen Flexoren und damit Unterbrechung der Reflexbahn erzeugt.

\section{Discussion}

HaRdy, A. G. (England) thought that Dr. Masse's paper emphasised that it was not so much that one method was better than another but that there were several methods already waiting from which to choose the best for any individual patient. In his paper to the Royal Society of Medicine some years ago, he had indicated that they had done a number of sciatic neurectomies, both complete and partial, and none of the cases of sciatic neurectomy had come to any harm because of it. They had also done a selective neurectomy of the nerves to the gluteus medius and maximus when they had had trouble with spasm there.

Guttmann, L. (England) said that from his experience he agreed with Dr. Hardy that it was not the method but how the method was done and that there were 'many roads which lead to Rome'; but, the main point was that before taking the knife a very careful assessment of the patient's condition was necessary to promote better results. One important point Dr. Masse had made was that in some cases sciatic neurectomy was preferable to elongation of the Achilles tendon. By severance of the peripheral nerves one eliminated all afferent impulses from the plantar surface of the foot. However, he was not absolutely convinced that division of the sciatic nerve did not produce awkward ulcers on the heel or sole. For those patients who did not walk it made no difference but in patients with incomplete lesions who had to walk long distances he would be reluctant to divide the sciatic nerve because of resulting trophic changes and the danger of sores developing. Dr. Masse's emphasis on resection of the flexors of the toes in plantar flexor spasticity was quite an important point. 